\title{
Dermcidin as a novel binding protein of IncRNA STCAT3 and its effect on prognosis in gastric cancer
}

\author{
JIANFENG ZHANG $^{1 *}$, WEIFENG DING ${ }^{2 *}$, XIAOLING KUAI ${ }^{1}$, YIMIN JI ${ }^{1}$, \\ ZHENGLONG ZHU ${ }^{1}$, ZHENBIAO MAO ${ }^{1}$ and ZHIWEI WANG ${ }^{3}$ \\ Departments of ${ }^{1}$ Gastroenterology, ${ }^{2}$ Laboratory Medicine and ${ }^{3}$ General Surgery, \\ The Affiliated Hospital of Nantong University, Nantong, Jiangsu 226001, P.R. China
}

Received January 4, 2018; Accepted August 17, 2018

DOI: $10.3892 /$ or.2018.6673

\begin{abstract}
Long non-coding RNAs (lncRNAs) perform distinct biological functions by regulating gene expression through various molecular mechanisms under normal physiological and pathological conditions. However, the function of the stomach cancer-associated transcript-3 (STCAT3) IncRNA, including its prognostic significance and role as a binding protein in gastric cancer (GC), remain unclear. In the present study, 56 potential binding proteins of STCAT3 were screened using through mass spectrometry and bioinformatics analysis. Among these, dermcidin, GAPDH, annexin, calmodulin-like protein, cathepsin-D and suprabasin were demonstrated to be candidate binding proteins using a literature search. RNA-protein interaction prediction was used to confirm these six proteins. Finally, dermcidin was identified as the binding protein of STCAT3 by comparing the mRNA and protein levels of the candidate genes and their correlations with STCAT3 in plasmid-transfected BGC-823 GC cell lines, as well as by validating the interplay between dermcidin and STCAT3 in other GC cell lines. Immunohistochemical analysis of tissues from 98 patients with GC further confirmed the interaction between dermcidin and STCAT3. The results of the present study also revealed that STCAT3 and dermcidin and independent predictors of overall survival in patients with GC. Furthermore STCAT3 and dermcidin are positively correlated with lymph node metastasis and tumor/node/metastasis score. In summary, the present study suggests that dermcidin
\end{abstract}

Correspondence to: Professor Zhenbiao Mao, Department of Gastroenterology, Affiliated Hospital of Nantong University, Nantong, Jiangsu 226001, P.R. China

E-mail:mzb1963@126.com

Professor Zhiwei Wang, Department of General Surgery, Affiliated Hospital of Nantong University, Nantong, Jiangsu 226001, P.R. China E-mail: 574267231@qq.com

*Contributed equally

Key words: stomach neoplasms, stomach cancer-associated transcript 3, dermcidin, prognosis is a novel binding protein of lncRNA STCAT3, which serves an important role in the progress and clinical outcome of GC.

\section{Introduction}

Gastric cancer (GC) is one of the most common malignant tumors and a major cause of cancer-associated mortality worldwide (1). Early diagnosis and effective treatment for GC are difficult to achieve as the underlying molecular mechanisms are unclear (2). As such, increasing our understanding of the mechanisms responsible for GC is crucial to allow for early diagnosis, effective therapy and survival prediction.

Long noncoding RNAs (lncRNAs) are RNAs >200 bp in length that are not directly translated into protein $(3,4)$. LncRNAs account for only 4-9\% of the mammalian transcriptome (5); however, a number of reports indicate that lncRNAs serve key roles in gene expression, gene imprinting, DNA recombination, chromatin modification, cell cycle regulation and encoding peptides (6-9). It has been reported that lncRNAs interact with genomic DNA and chromatin in the following ways: i) Forming a DNA-RNA heteroduplex by binding to regions of single-stranded DNA; ii) forming DNA-DNA-RNA triplexes by Hoogsteen or reverse Hoogsteen base pairing; iii) tethering to chromatin through association with RNA polymerase II and thereby acting as allele-specific signatures for a specific locus; iv) indirectly binding to chromatin by binding to chromatin-associated proteins or transcription factors; and v) directly forming sense chromatin structures (10). LncRNA is able to exert a wide range of regulatory functions, including on cell growth, apoptosis, migration, invasion and autophagy (11).

A previous study by our research group revealed that lncRNA STCAT3 overexpression promoted the proliferation and invasion of GC cells and that STCAT3 interference significantly inhibited GC (12). However, the potential pathological mechanisms of STCAT3 and its prognostic significance in patients with GC remain uncertain. The aim of the present study was to screen and identify proteins that interact with STCAT3 by using RNA pull-down technology and mass spectrometry. Reverse transcription-quantitative polymerase chain reaction (RT-qPCR) and western blotting were used to measure mRNA and protein expression, respectively. RNA binding protein immunoprecipitation (RIP) experiments were also performed. The prognostic value of STCAT3 and 
its binding protein in GC was evaluated using univariate Cox proportional hazards regression models.

\section{Materials and methods}

Patients and clinical samples. The present study was approved by the institutional review board of the Affiliated Hospital of Nantong University (Nantong, China) and performed according to the Declaration of Helsinki. Written informed consent was obtained from all patients prior to the experiments. A total of 98 patients (32-84 years old; male: female, 63: 35) with GC were recruited at the Department of General Surgery, the Affiliated Hospital of Nantong University between May 2014 and December 2016. GC tissues and pair-matched normal gastric tissues ( $5 \mathrm{~cm}$ adjacent to carcinoma tissue) were harvested. No patients had previously undergone chemotherapy, radiotherapy or treatment with long-term anti-inflammatory nonsteroidal drugs or corticosteroids prior to surgery. Cancer classification and pathological typing was performed by two experienced pathologists in a double-blind manner.

Cell culture and transfection. The human GC cell lines AGS, MGC-803, BGC-823, MKN-28, MKN-45 and SGC-7901 and the normal human gastric mucosa cell line GES-1 were purchased from the Shanghai Institutes for Biological Sciences (Chinese Academy of Sciences, Shanghai, China). Cells were cultured in RPMI-1640 culture medium (HyClone; GE Healthcare Life Sciences, Logan, UT, USA) containing $10 \%$ fetal bovine serum (Zhejiang Tianhang Biotechnology Co., Ltd., Hangzhou, China), $100 \mu \mathrm{g} / \mathrm{ml}$ streptomycin, and $100 \mathrm{U} / \mathrm{ml}$ penicillin at $37^{\circ} \mathrm{C}$ in an atmosphere containing $5 \%$ $\mathrm{CO}_{2}$. STCAT3-overexpression plasmid (STCAT3-pCDNA3.1), negative control vector (pCDNA3.1), STCAT3 knockdown plasmid [pGPU6/GFP/Neo-STCAT3-short hairpin (sh) RNA, sh-STCAT3], and negative control vector (sh-NC) were constructed and synthesized by Shanghai GenePharma Co., Ltd (Shanghai, China). Cells in the log phase were selected and transfected with $4.0 \mu \mathrm{g} /$ well plasmid DNA in 24 -well plates $\left(5 \times 10^{5}\right.$ cells/well) at $85 \%$ confluence using Lipofectamine ${ }^{\circledR} 2000$ (Invitrogen; Thermo Fisher Scientific, Inc., Waltham, MA, USA). Cells were dissociated using a solution containing 0.25\% trypsin EDTA (Sigma-Aldrich; Merck KGaA, Darmstadt, Germany). Primer sequences used for plasmid construction are provided in Table I. Subsequent experiments were performed $72 \mathrm{~h}$ post-transfection.

In vitro transcription assays and RNA pull down assays. Primers were designed and synthesized by Wuhan GeneCreate Biological Engineering Co.,Ltd. (Wuhan, China). The STCAT3 gene primer sequences were as follows: Sense chain, forward 5'-TAATACGACTCACTATAGGGGTCTATTTGATTCTTC TCTC-3' and reverse 5'-GGAGCTGAAAAACACAGC-3'; antisense chain, forward 5'-TAATACGACTCACTATAGGGG GAGCTGAAAAACACAGCAT-3' and reverse 5'-GTCTAT TTGATTCTTCTCTC-3'. In vitro amplification of the sense and antisense chains was performed to obtain DNA templates; in vitro transcription reactions were then performed using a MAXIscript ${ }^{\circledR}$ T7 Transcription kit (no. AM1312, Ambion; Thermo Fisher Scientific, Inc.) according to the manufacturer's protocol. STCAT3 RNAs were labeled by desthiobiotinylation using a Pierce ${ }^{\mathrm{TM}}$ RNA 3' End Desthiobiotinylation kit (no. 20163; Thermo Fisher Scientific, Inc.) according to the manufacturer's protocol. RNA pulldown assays were then performed using a Pierce ${ }^{\mathrm{TM}}$ Magnetic RNA-Protein Pull-Down kit (no. 20164; Thermo Fisher Scientific, Inc.) according to the manufacturer's protocol.

Mass spectrometry. Proteomic detection of the purified RNA-binding proteins was achieved using mass spectrometry. Briefly, $10 \mathrm{mM}$ dithiothreitol (DTT) and $55 \mathrm{mM}$ iodoacetamide (IAM) were added into the polyacrylamide gel electrophoresis (PAGE) gel along with a trypsin enzyme (Beijing Biodee Diagnostics, Beijing, China) to enzymatically hydrolyze overnight. The resulting peptides were treated with a $\mathrm{C} 18$ column (YMC Co., Ltd., Shanghai, China) and then dissolved in $15 \mu \mathrm{l}$ loading buffer ( $0.1 \%$ formic acid and $3 \%$ acetonitrile). Peptides were investigated using LC-MS/MS (ekspert ${ }^{\mathrm{TM}}$ nanoLC, TripleTOF 5600-plus; SCIEX, Framingham, MA, USA). Data were analyzed using ProteinPilot ${ }^{\mathrm{TM}}$ Software version 4.5 (SCIEX) with Triple TOF 5600-plus for database retrieval (UniProt, June 2016; http://www.uniprot. org/proteomes/UP000005640) to obtain the possible interacting proteins.

RNA immunoprecipitation analysis (RIP). RIP experiments were performed using a Magna RIP ${ }^{\text {тм }}$ RNA-Binding Protein Immunoprecipitation kit (EMD Millipore, Billerica, MA, USA) according to the manufacturer's protocol. The dermcidin antibody used for RIP was from Abcam (1:20; cat. no. ab52138, Cambridge, UK). An aliquot of mouse IgG (1:20; cat. no. ab190475, Abcam) served as the input control. Messenger RNAs of cells were isolated, then samples RNA enrichment was determined by RT-qPCR as described in the following section and normalized to the input control. Data was from triplicate experiments.

$R N A$ extraction and $R T-q P C R$. Total RNA was extracted from tissues and cells using TRIzol reagent (Invitrogen; Thermo Fisher Scientific, Inc.) according to the manufacturer's protocol. cDNA was obtained using a PrimeScript ${ }^{\mathrm{TM}}$ RT Reagent kit (cat. no. RR014A; Takara Biotechnology, Co., Ltd., Dalian, China) according to the manufacturer's protocol. The temperature protocol was as follows: $42^{\circ} \mathrm{C}$ for $60 \mathrm{~min}$ and $70^{\circ} \mathrm{C}$ for $5 \mathrm{~min}$. qPCR was performed using SYBRGreen I (Takara Biotechnology, Co., Ltd.) and an Applied Biosystems 7500 Real-Time PCR System (Thermo Fisher Scientific, Inc.) according to the manufacturer's protocol. The primers were synthesized by GeneCreate (Wuhan, China) and are presented in Table II. Relative gene expression was calculated with $\beta$-actin as a control. The PCR system comprised the following: $25 \mu \mathrm{l}$ SYBR Premix Ex Taq ${ }^{\mathrm{TM}}(2 \mathrm{X}), 2 \mu \mathrm{l}$ PCR forward primer, $2 \mu \mathrm{l}$ PCR reverse primer, $4 \mu \mathrm{l}$ PCR template (cDNA solution), $1 \mu \mathrm{l}$ ROX Reference Dye (50X) and $16 \mu 1$ sterile double steamed water. Thermocycling conditions were as follows: $95^{\circ} \mathrm{C}$ for $30 \mathrm{sec}, 95^{\circ} \mathrm{C}$ for $5 \mathrm{sec}$ and $60^{\circ} \mathrm{C}$ for $30 \mathrm{sec}$. Data were quantified using the $2^{-\Delta \Delta \mathrm{Cq}}$ method (13). Each RT-qPCR experiment was performed in triplicate. Tumor tissues were assigned to the high expression group when STCAT3 expression was two fold higher compared with adjacent normal tissues. 
Table I. Primers used for shRNA plasmid construction.

\begin{tabular}{lll}
\hline shRNA & Direction & \multicolumn{1}{c}{ Sequence (5'-3') } \\
\hline STCAT3 shRNA & Sense & $\begin{array}{l}\text { CACCGTACGCTTCACAAGGTTCTCATTCAAGAGATGAGAACCTTGTGAAGCGTAC } \\
\text { TTTTTG }\end{array}$ \\
& Antisense & $\begin{array}{l}\text { GATCCAAAAAAGTACGCTTCACAAGGTTCTCATCTCTTGAATGAGAACCTTGTGA } \\
\text { AGCGTAC }\end{array}$ \\
& & CACCGTTCTCCGAACGTGTCACGTCAAGAGATTACGTGACACGTTCGGAGAATTT \\
Control shRNA & Sense & TTTG \\
& Antisense & GATCAAAAAAGTTCTCCGAACGTGTCACGTAATCTCTTGACGTGACACGTTCGG \\
& & AGAAC \\
\end{tabular}

shRNA, short hairpin RNA; STCAT3, stomach cancer-associated transcript 3.

Table II. Primers used for reverse transcription-quantitative polymerase chain reaction.

\begin{tabular}{lll}
\hline Gene & \multicolumn{1}{c}{ Forward (5'-3') } & \multicolumn{1}{c}{ Reverse (5'-3') } \\
\hline STCAT3 & CCACTGTTTGTCTGATGGGC & AGCAAGACAAGCCAGCATTC \\
Dermcidin & TCTTTGGGGCTCCTGTGAATC & CTGCTGCTCCTGGGTATCATT \\
Suprabasin & AAATAGCAGCGTGGCTTCCC & AGTAGCAGAAGGAGGGAGCA \\
Cathepsin D & TGCTCAAGAACTACATGGACGC & CGAAGACGACTGTGAAGCACT \\
Calmodulin & TACGAGGAGTTCGCGAGGAT & AGAGTCCCAGCACAAAAGCA \\
Annexin A2 & TGCCTTCGCCTACCAGAGAA & GCCCAAAATCACCGTCTCC \\
GAPDH & AGAAGGCTGGGGCTCATTTG & AGGGGCCATCCACAGTCTTC \\
$\beta$-actin & AGCGAGCATCCCCCAAAGTT & GGGCACGAAGGCTCATCATT
\end{tabular}

STCAT3, stomach cancer-associated transcript 3.

Western blotting. Western blotting was performed to assess the expression of dermcidin, GAPDH, calmodulin, cathepsin D, suprabasin, Annexin A2 and $\beta$-actin proteins as described previously (14). Briefly, cells were rapidly homogenized in a buffer containing $10 \mu \mathrm{g} / \mathrm{ml}$ leupeptin, $1 \%$ Triton $\mathrm{X}-100,10 \%$ sodium dodecyl sulfate (SDS), $1 \mathrm{M}$ Tris- $\mathrm{HCl}$ ( $\mathrm{pH} 7.5), 0.5 \%$ sodium deoxycholate, $10 \mu \mathrm{g} / \mathrm{ml}$ aprotinin, $1 \%$ Nonidet $^{\mathrm{TM}}$ $\mathrm{P}-40,1 \mathrm{mM}$ phenylmethylsulfonyl fluoride and $0.5 \mathrm{M}$ ethylenediaminetetraacetic acid, following which they were centrifuged at $10,000 \mathrm{x}$ g for $30 \mathrm{~min}$ at $4^{\circ} \mathrm{C}$ and collect the supernatant. Protein concentrations were determined using a Bio-Rad protein assay (Bio-Rad Laboratories, Inc., Hercules, CA, USA). Equal amounts of protein (40 $\mu \mathrm{g} /$ lane) were separated by $15 \%$ SDS-PAGE and transferred to polyvinylidene difluoride membranes. The membranes were blocked with $5 \%$ dried skimmed milk in Tris-buffered saline and Tween-20 containing $0.05 \%$ Tween-20, $20 \mathrm{mM}$ Tris, and $150 \mathrm{mM} \mathrm{NaCl}$ for $2 \mathrm{~h}$ at room temperature. Membranes were incubated at $4^{\circ} \mathrm{C}$ overnight with the following monoclonal primary antibodies: Rabbit anti-dermcidin (cat. no. ab52138), rabbit anti-GAPDH (cat. no. ab181602), rabbit anti-calmodulin (cat. no. ab45689), rabbit anti-cathepsin D (cat. no. ab75852), rabbit anti-suprabasin (cat. no. ab232771) and rabbit anti-Annexin A2 (cat. no. ab178677; all 1:2,000; all Abcam). Mouse anti- $\beta$-actin (cat. no. ab8226; $1: 2,000$; Abcam) monoclonal antibody was used as an internal control. Horseradish peroxidase (HRP)-conjugated goat anti-rabbit IgG H\&L (1:10,000; cat. no. ab97051; Abcam) and rabbit anti-mouse IgG H\&L cat. no. ab6728; 1:5,000; Abcam) were used as secondary antibodies for $2 \mathrm{~h}$ at room temperature. The proteins were visualized using an enhanced chemiluminescent detection system (GE Healthcare Life Sciences, Little Chalfont, UK), according to the manufacturer's protocol. Following chemiluminescence, bands were exposed to X-ray films (Kodak, Rochester, NY, USA) and ImageJ 1.37 software (National Institutes of Health, Bethesda, MD, USA) was used for grey value analysis. Relative amounts of proteins were quantified by absorbance analysis and normalized to $\beta$-actin. The experiments were repeated three times.

Immunohistochemistry. Tumor and adjacent normal tissues were fixed in $10 \%$ buffered formalin for $24 \mathrm{~h}$ at room temperature, embedded in paraffin and cut into sections $(4 \mu \mathrm{m})$. The sections were deparaffinized in xylene, rehydrated in graded ethanol solutions and treated with $0.1 \%$ hydrogen peroxide in methanol for $20 \mathrm{~min}$ to remove endogenous peroxidase activity. Antigen retrieval was performed by microwaving the sections immersed in $10 \mathrm{mM}$ citric acid buffer for $10 \mathrm{~min}$, followed by 1 -h incubation at room temperature. To block non-specific protein binding, sections were incubated with $5 \%$ bovine serum albumin (cat. no. LLBB-1000-01; SurModics, Inc., Eden Prairie, USA) for $10 \mathrm{~min}$ at $37^{\circ} \mathrm{C}$. Sections were incubated at 
room temperature for $1 \mathrm{~h}$ with monoclonal antibody against dermcidin (cat. no. ab52138; 1:50; Abcam) and again overnight at $4^{\circ} \mathrm{C}$. Sections were washed with PBS and incubated with HRP-conjugated polyclonal goat anti-rabbit IgG (H\&L) biotin secondary antibodies (cat. no. E030110-01; 1:500; EarthOx, LLC, San Francisco, CA, USA) for $1 \mathrm{~h}$ at room temperature, followed by $0.1 \%$ hydrogen peroxide and $0.6 \mathrm{mM} \mathrm{3,3'-diaminobenzidine}$ (DAB) in PBS for $8 \mathrm{~min}$ at room temperature. Omission of the primary antibody served as a negative control. All sections were counterstained with hematoxylin for $2 \mathrm{~min}$ at room temperature and examined using a light microscope (BX51; Olympus Corporation, Tokyo, Japan; magnification, x100 and x400). Two consultant pathologists assessed slides in a blinded fashion. Staining was evaluated as previously described (14).

Statistical analysis. All statistical analyses were performed using SPSS 17.0 (SPSS, Inc., Chicago, IL, USA), and graphs were generated using GraphPad Prism software version 5.0 (GraphPad Software, Inc., La Jolla, CA, USA). Differences between groups were analyzed using Student's t-test, one-way analysis of variance, the $\chi^{2}$ test, Spearman's rank correlation coefficient or Pearson's correlation coefficient, as appropriate. Student-Newman-Keuls post hoc test was performed following ANOVA. Variables associated with overall survival (OS) and time to recurrence (TTR) were assessed using univariate Cox proportional hazard regression models. Kaplan-Meier plots (log-rank tests) were used to describe OS and TTR. $\mathrm{P}<0.05$ was considered to indicate a statistically significant difference.

\section{Results}

STCAT3 is highly expressed in GC tissues. The expression of STCAT3 was detected in 98 paired GC tissues and adjacent normal tissues using RT-qPCR normalized to $\beta$-actin. STCAT3 expression in GC tissues was significantly higher compared with in the adjacent normal gastric tissues $(\mathrm{P}<0.05$; Fig. 1A). The expression of STCAT3 varied dramatically between GC cell lines, however it was upregulated in all GC cell lines compared with the normal gastric mucosa cell line GES-1 (all $\mathrm{P}<0.05$ ). In particular, STCAT3 expression was much higher in BGC-823, MKN-45 and SGC-7901 compared with the GES-1 cell line (Fig. 1B).

STCAT3 is and is associated with advanced clinical stage and poor survival. The clinical features of patients with GC are presented in Table III. STCAT3 expression in GC tissues was positively correlated with TNM stage and lymph node metastasis; patients with GC of TNM stages III/IV had significantly higher STCAT3 expression compared with those with GC at stages I/II ( $\mathrm{P}<0.05$; Fig. 1C). Furthermore, patients with positive lymph node metastasis had significantly higher STCAT3 expression compared with patients with no lymph node metastasis $(\mathrm{P}<0.05$; Fig. 1D). Other clinical characteristics, including histological grade, invasion depth, sex and age, were not correlated with STCAT3 expression.

Kaplan-Meier analysis and log-rank test were performed to determine the association between the STCAT3 expression in GC tissues and patient prognosis. The median time until postoperative recurrence in the patients with high STCAT3 expression levels was significantly shorter compared with
Table III. The association between STCAT3 expression and clinical characteristics.

\begin{tabular}{|c|c|c|c|c|}
\hline \multirow[b]{2}{*}{ Clinical characteristics } & \multirow[b]{2}{*}{$\mathrm{N}$} & \multicolumn{2}{|c|}{$\begin{array}{c}\text { STCAT3 } \\
\text { expression }\end{array}$} & \multirow[b]{2}{*}{ P-value } \\
\hline & & Low & $\operatorname{High}^{\mathrm{a}}$ & \\
\hline Age (years) & & & & 0.478 \\
\hline$<60$ & 41 & 8 & 33 & \\
\hline$\geq 60$ & 57 & 15 & 42 & \\
\hline Sex & & & & 0.804 \\
\hline Male & 63 & 14 & 49 & \\
\hline Female & 35 & 9 & 26 & \\
\hline Tumor size (cm) & & & & 0.456 \\
\hline$<5$ & 65 & 17 & 48 & \\
\hline$\geq 5$ & 33 & 6 & 27 & \\
\hline Invasion depth & & & & 0.096 \\
\hline $\mathrm{T} 1 / \mathrm{T} 2$ & 44 & 14 & 30 & \\
\hline $\mathrm{T} 3 / \mathrm{T} 4$ & 54 & 9 & 45 & \\
\hline TNM phase & & & & 0.001 \\
\hline $\mathrm{I} / \mathrm{II}$ & 41 & 17 & 24 & \\
\hline III/IV & 57 & 6 & 51 & \\
\hline Differentiation degree & & & & 1 \\
\hline High or mid & 48 & 11 & 37 & \\
\hline Low & 50 & 12 & 38 & \\
\hline Lymph node metastasis & & & & 0.025 \\
\hline No & 35 & 13 & 22 & \\
\hline Yes & 63 & 10 & 53 & \\
\hline
\end{tabular}

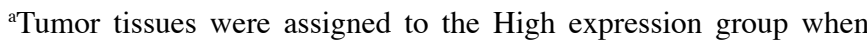
STCAT3 expression was two fold higher compared with adjacent normal tissues. STCAT3, stomach cancer-associated transcript 3.

the low STCAT3 group ( $\mathrm{P}<0.05$; Fig. 1D). Furthermore, the median survival time in the low STCAT3 expression group was significantly longer compared with the high expression group $(\mathrm{P}<0.05$; Fig. 1E).

Screening and identification of dermcidin as a novel binding protein of lncRNA STCAT3. STCAT3 was used to capture its interacting protein using the BGC-823 cell line. A notable difference was observed between the sense and antisense strands of STCAT3 following electrophoresis silver staining. The protein of band 2 was decomposed and analyzed using mass spectrometry (Fig. 2A). Species database retrieval and bioinformatics analysis were performed and 56 proteins were different regarding statistics or function (data not shown).

Mounting studies have reported that dermcidin (15-17), GAPDH $(18)$, annexin $(19,20)$, calmodulin-like protein $(21,22)$, cathepsin-D (23) and suprabasin (24) are associated with malignant tumors. Based on this, RNA-protein interaction prediction was used to assess whether these proteins were binding candidates for STCAT3. The interaction probabilities for all proteins were $>0.5$, suggesting that these proteins may be candidate binding proteins for STCAT3. 

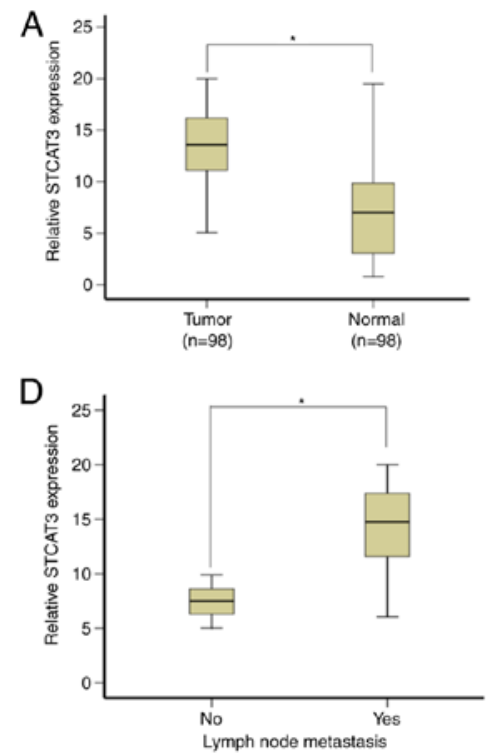

B

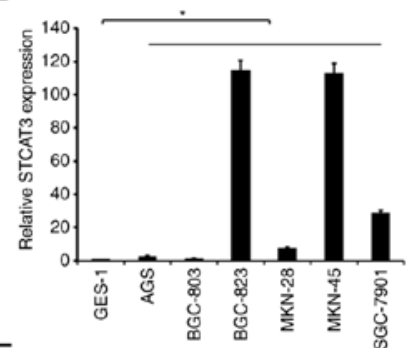

E

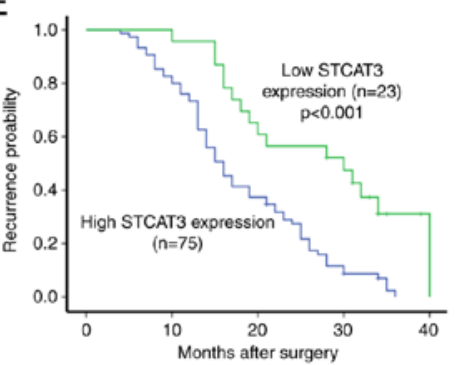

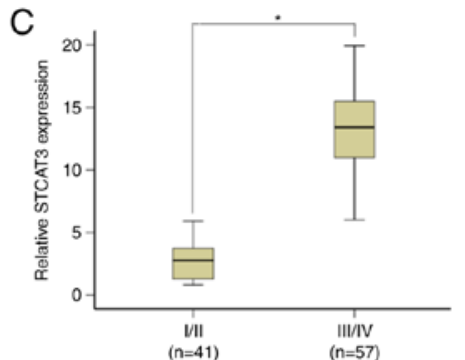

$\mathrm{F}$

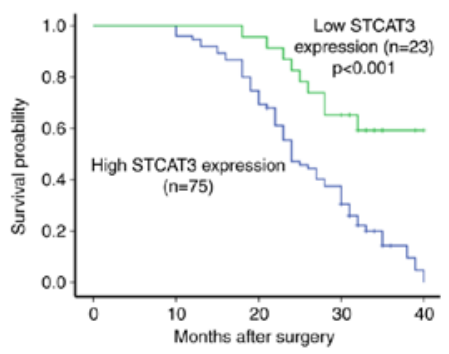

Figure 1. STCAT3 expression in GC cell lines cell lines and tumor tissues. STCAT3 expression was detected in (A) 98 GC tissue samples and (B) AGS, MGC-803, BGC-823, MKN-28, MKN-45 and SGC-7901 GC cell lines using reverse transcription-quantitative polymerase chain reaction. Paired adjacent tissues and the normal gastric mucosa cell line GES-1 were used as negative controls, respectively. The association between STCAT3 expression and (C) TNM stage or (D) lymph node metastasis was assessed. (E) Postoperative recurrence and (F) survival times in patients with high or low STCAT3 expression were evaluated by log-rank test. ${ }^{*} \mathrm{P}<0.05$. STCAT3, stomach cancer-associated transcript 3; GC, gastric cancer.

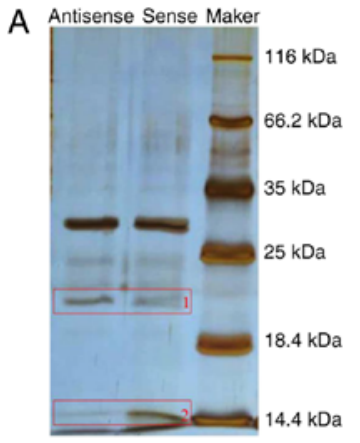

B
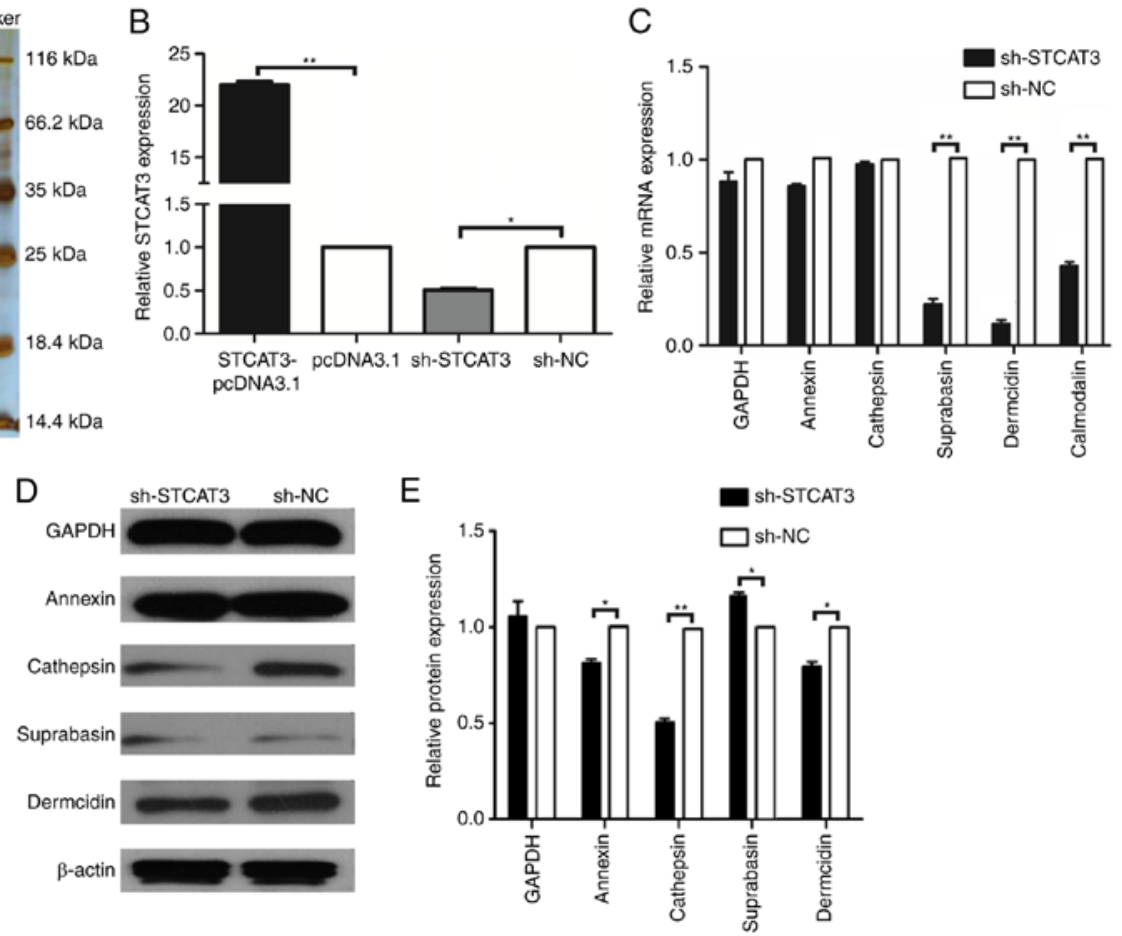

Figure 2. Screening and identification of candidate lncRNA STCAT3 binding proteins. (A) Silver electrophoresis staining with the sense and antisense RNA of IncRNA STCAT3. Reverse transcription-quantitative polymerase chain reaction was used to assess (B) STCAT3 expression in the STCAT3-pCDNA3.1, pCDNA3.1, STCAT3-shRNA and sh-NC groups, respectively, and (C) the expression of annexin, cathepsin-D, suprabasin, dermcidin, and calmodulin mRNA in BGC-823 cells following transfection. (D and E) Western blotting was uses to measure the expression of annexin, cathepsin-D, suprabasin, dermcidin, and calmodulin-like proteins in the sh-STCAT3 and sh-NC groups. $\beta$-actin was used as a reference control. "** $\mathrm{P}<0.001$ and "P<0.05. lncRNA, long non-coding RNA; STCAT3, stomach cancer-associated transcript 3; sh, short hairpin RNA; NC, negative control.

To identify the binding protein for STCAT3, the plasmid vectors STCAT3-pCDNA3.1, pCDNA3.1, sh-STCAT3 and sh-NC were transfected into BGC-823 cells. STCAT3 expression in the STCAT3-pCDNA3.1 group was significantly higher compared with the pCDNA3.1 group ( $\mathrm{P}<0.001$; Fig. $2 \mathrm{~B})$. In contrast, STCAT3 expression in the sh-STCAT3 group was decreased compared with the sh-NC group $(\mathrm{P}<0.001$; Fig. 2B). RT-qPCR was used to measure the mRNA expression of 
A

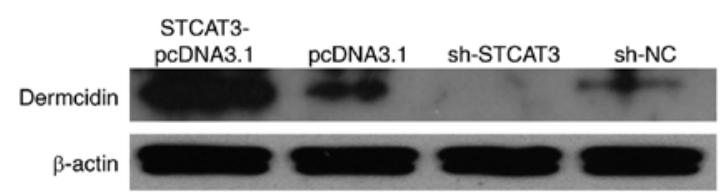

C

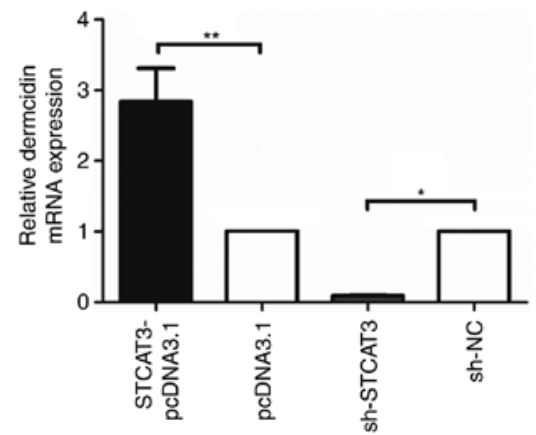

$\mathrm{B}$

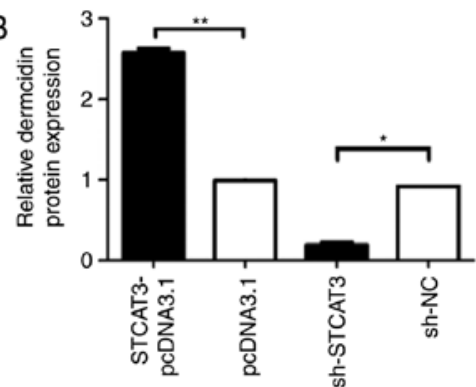

D

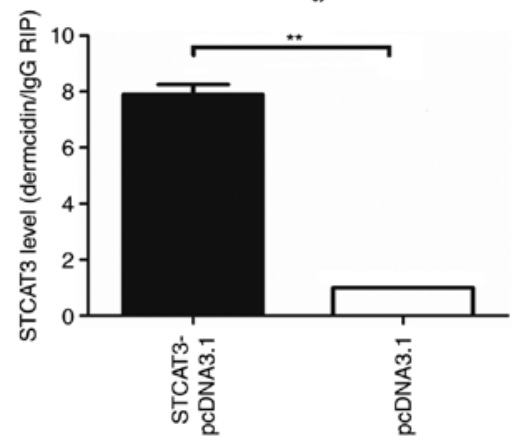

Figure 3. Validation of the lncRNA STCAT3 novel binding protein. (A) Western blotting was performed and (B) quantified to assess the expression of dermcidin in the STCAT3-pCDNA3.1 and pCDNA3.1 plasmid groups. $\beta$-actin was used as a reference control. (C) Reverse transcription-quantitative polymerase chain reaction was used to assess the expression of dermcidin mRNA expression in STCAT3-pCDNA3.1 and sh-STCAT3 cells. (D) RNA immoprecipitation-qPCR was to verify the interaction between $\operatorname{lncRNA}$ STCAT3 and Dermcidin. ${ }^{* *} \mathrm{P}<0.001$ and ${ }^{*} \mathrm{P}<0.05$. IncRNA, long non-coding RNA; STCAT3, stomach cancer-associated transcript 3 ; sh, short hairpin RNA; NC, negative control; IgG, immunoglobulin G.

the potential binding proteins in the sh-STCAT3 and sh-NC groups. Dermcidin, suprabasin and calmodulin-like proteins were significantly downregulated in the sh-STCAT3 group compared with the sh-NC group $(\mathrm{P}<0.05$; Fig. $2 \mathrm{C})$. However, the expression of annexin, cathepsin-D and GAPDH was not significantly different between groups. Furthermore, dermcidin, suprabasin and calmodulin-like protein expression was positively correlated with lncRNA STCAT3 expression (Pearson $\mathrm{r}=0.985,0.932$ and $0.941 ; \mathrm{P}<0.05$ ), suggesting that they were candidate STCAT3 binding proteins.

In contrast, the results of western blotting (Fig. 2D) revealed that dermcidin, annexin and cathepsin D protein expression in the sh-STCAT3 group was significantly lower compared with the sh-NC group $(\mathrm{P}<0.05$; Fig. $2 \mathrm{E})$. These protein levels were positively correlated with STCAT3 expression (Pearson $r=0.967,0.868,0.971 ; \mathrm{P}<0.05)$. Suprabasin protein expression was significantly increased in the sh-STCAT3 group compared with the sh-NC group and was negatively correlated with STCAT3 (Pearson $r=-0.951$; $P<0.05$; Fig. 2E). As such, in terms of protein expression, dermcidin, annexin and cathepsin D were identified as potential binding proteins of STCAT3. Based on these above results, dermcidin was identified as a novel binding protein that can interact with the IncRNA STCAT3.

Validation of dermcidin as a novel binding protein of lncRNA STCAT3. To confirm dermcidin as a novel binding protein of STCAT3, dermcidin expression was measured in a number of GC cell lines. RT-qPCR and western blotting revealed that dermcidin expression was significantly increased in the STCAT3-pCDNA3.1 group compared with the pCDNA3.1 group $(\mathrm{P}<0.001$; Fig. 3A-C). However, dermcidin expression was significantly lower in the sh-STCAT3 group compared with the sh-NC group $(\mathrm{P}<0.01$; Fig. 3A-C).
Table IV. Association between Dermcidin expression and clinical characteristics.

\begin{tabular}{|c|c|c|c|c|}
\hline \multirow[b]{2}{*}{ Clinical characteristics } & \multirow[b]{2}{*}{$\mathrm{N}$} & \multicolumn{2}{|c|}{$\begin{array}{l}\text { Dermcidin } \\
\text { expression }\end{array}$} & \multirow[b]{2}{*}{ P-value } \\
\hline & & - & + & \\
\hline Age (years) & & & & 0.21 \\
\hline$<60$ & 41 & 12 & 29 & \\
\hline$\geq 60$ & 57 & 24 & 33 & \\
\hline Sex & & & & 0.194 \\
\hline Male & 63 & 20 & 43 & \\
\hline Female & 35 & 16 & 19 & \\
\hline Tumor size (cm) & & & & 1 \\
\hline$<5$ & 65 & 24 & 41 & \\
\hline$\geq 5$ & 33 & 12 & 21 & \\
\hline Invasion depth & & & & 0.058 \\
\hline $\mathrm{T} 1 / \mathrm{T} 2$ & 44 & 21 & 23 & \\
\hline T3/T4 & 54 & 15 & 39 & \\
\hline TNM stage & & & & 0.005 \\
\hline $\mathrm{I} / \mathrm{II}$ & 41 & 22 & 19 & \\
\hline III/IV & 57 & 14 & 43 & \\
\hline Differentiation degree & & & & 0.012 \\
\hline High or mid & 48 & 24 & 24 & \\
\hline Low & 50 & 12 & 38 & \\
\hline Lymph node metastasis & & & & 0.002 \\
\hline No & 35 & 20 & 15 & \\
\hline Yes & 63 & 16 & 47 & \\
\hline
\end{tabular}

+, overexpression; -, downexpression or absent. 

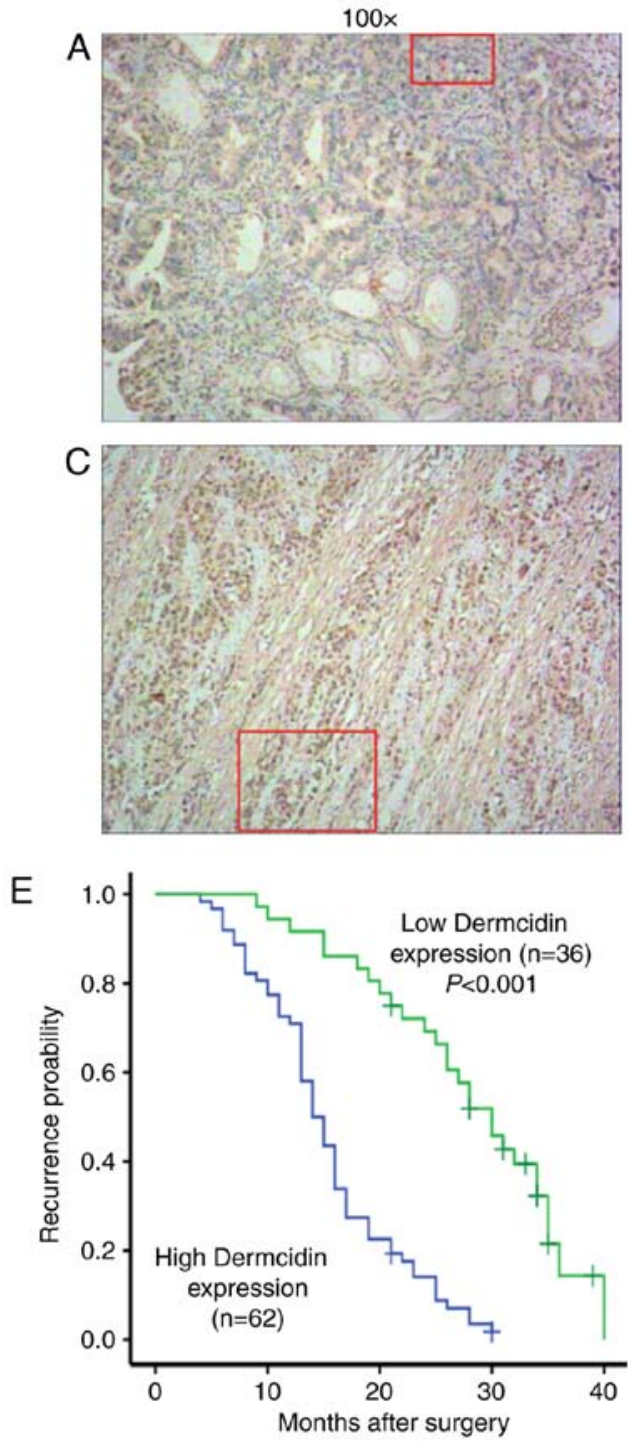
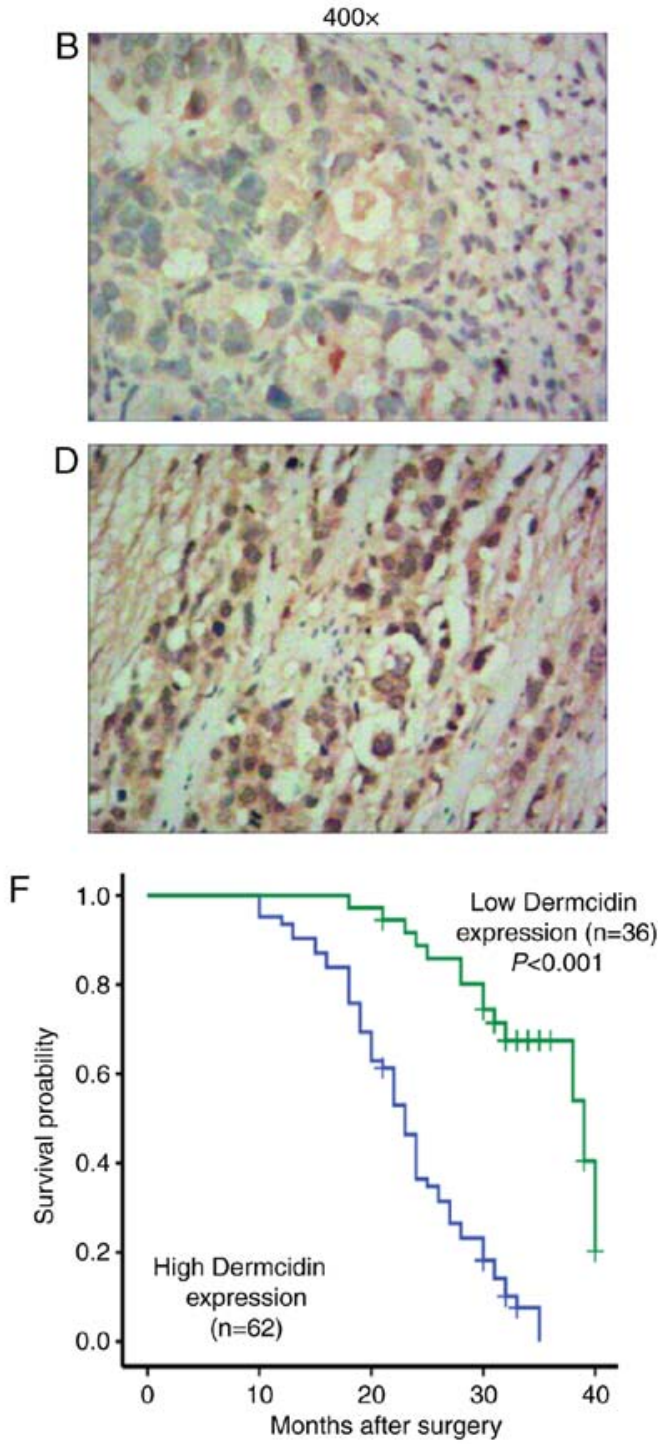

Figure 4. Dermcidin expression is negatively correlated with survival in patients with GC. (A and B) High and (C and D) low differentiation adenocarcinoma tissues were stained to assess dermcidin expression and images were captured. Brown coloration indicates positive staining. Patients were divided into high and low dermcidin expression groups and their (E) postoperative recurrence times and (F) overall survival were evaluated using Kaplan-Meier analysis.

To confirm direct binding between IncRNA STCAT3 and dermcidin, RIP-qPCR was performed to measure STCAT3 expression in the STCAT3-pCDNA3.1 and pCDNA3.1 groups. LncRNA STCAT3 co-immunoprecipitated by the protein dermcidin was significantly higher in the STCAT3-pCDNA3.1 group compared with the pCDNA3.1 group $(\mathrm{P}<0.001$; Fig. 3D). These data suggest that dermcidin is the direct-binding protein of IncRNA STCAT3.

Dermcidin expression is positively correlated with STCAT3 and poor survival in patients with GC. The expression of dermcidin was measured in GC tissues from 98 patients with GC using immunohistochemistry. Positive staining for dermcidin was localized to the cell nucleus and cytoplasm in GC tissues (Fig. 4A-D). The rate of dermcidin expression was $63.26 \%$ (62/98) in GC tissues, whereas it was weakly expressed in normal adjacent tissues. Dermcidin expression was also demonstrated to be significantly associated with clinical TNM stage, tumor differentiation and lymph node metastasis (all $\mathrm{P}<0.05$; Table IV).
Table V. The correlation between STCAT3 and Dermcidin protein expression in patients with GC.

\begin{tabular}{lrrr}
\hline & \multicolumn{2}{c}{ Dermcidin } & \\
\cline { 2 - 3 } STCAT3 & + & - & Sum \\
\hline+ & 58 & 17 & 75 \\
- & 4 & 19 & 23 \\
Sum & 62 & 36 & 98 \\
\hline
\end{tabular}

+ overexpression; -, downexpression or absent; Sum, Summary Spearman related coefficient $r=0.5270, \mathrm{P}<0.001$

Spearman's rank correlation between STCAT3 mRNA and dermcidin protein expressions in human GC tissue samples was calculated and a positive correlation was observed between STCAT3 and dermcidin protein expression in GC tissues $(\mathrm{r}=0.5270 ; \mathrm{P}<0.001$; Table V). 
Table VI. Univariate and multivariate analysis of clinical factors associated with survival in patients with GC.

\begin{tabular}{lccccccc}
\hline & \multicolumn{3}{c}{ Univariate analysis } & & \multicolumn{3}{c}{ Multivariate analysis } \\
\cline { 2 - 3 } Risk factor & HR & $95 \%$ CI & P-value & & HR & $95 \%$ CI & P-value \\
\hline Age & 0.764 & $0.237-1.599$ & 0.709 & & 0.517 & $0.227-1.412$ & 0.211 \\
Sex & 0.892 & $0.434-2.211$ & 0.843 & & 1.478 & $0.461-3.473$ & 0.474 \\
Tumor size & 1.18 & $0.499-2.865$ & 0.714 & & 1.167 & $0.414-3.062$ & 0.922 \\
Invasion depth & 2.238 & $0.974-4.234$ & 0.062 & & 0.617 & $0.213-2.612$ & 0.439 \\
TNM stage (I/II/III/IV) & 6.835 & $2.338-16.427$ & 0.001 & & 5.558 & $1.240-25.513$ & 0.014 \\
Differentiation degree (high/middle/low) & 3.495 & $1.438-8.438$ & 0.097 & & 3.502 & $1.226-10.316$ & 0.129 \\
Lymph node metastasis (no/yes) & 4.33 & $1.874-12.208$ & 0.027 & & 3.243 & $1.127-9.247$ & 0.145 \\
STCAT3 expression & 13.828 & $3.847-37.180$ & 0.001 & & 10.61 & $2.079-47.012$ & 0.006 \\
Dermcidin expression & 7.24 & $2.151-24.913$ & 0.002 & & 6.395 & $1.424-26.969$ & 0.019 \\
\hline
\end{tabular}

GC, gastric cancer; HR, hazard ratio; CI, confidence interval; STCAT3, stomach cancer-associated transcript 3.

To investigate the association between dermcidin expression and GC prognosis, Kaplan-Meier analysis and the log-rank test were performed. The median time until postoperative recurrence and median survival duration were significant higher in the low dermcidin expression group compared with the high expression group $(\mathrm{P}<0.001$; Fig. $4 \mathrm{E}$ and $\mathrm{F})$, indicating that dermcidin overexpression is a predictor of poor prognosis in patients with GC.

To confirm the prognostic value of STCAT3 and dermcidin expression in patients with GC, univariate and multivariate survival analyses (Cox proportional hazards regression model) were performed. The univariate analysis included ten prognostic factors: Age, sex, tumor size, invasion depth, TNM stage, differentiation grade, lymph node metastasis, STCAT3 expression and dermcidin expression. The results revealed that STCAT3 and dermcidin expression are independent predictors of $\mathrm{OS}(\mathrm{P}<0.05)$ and TNM stage $(\mathrm{P}=0.014)$ in patients with GC (Table VI).

\section{Discussion}

Despite advances in surgery, chemotherapy and targeted molecular therapies, GC remains a leading contributor to cancer-associated mortality worldwide $(1,25)$. Developing a better understanding of the molecular mechanisms underlying the development and progression of GC may allow for early diagnostic and treatment methods to be developed, improving the, overall prognosis.

A number of studies have reported that lncRNAs serve vital roles in a range of human diseases, including GC and other cancers $(26,27)$, functioning as potential oncogenes or tumor suppressors (28-31). For example, HOTAIR expression is upregulated in GC tissues and is an independent predictor of poor prognosis and HOTAIR knockdown in GC cells suppresses the migration and invasion of GC cells; this suggests that HOTAIR functions as a novel oncogene in GC $(32,33)$. LncRNA gastric carcinoma high expressed transcript 1 overexpression is associated with gastric tumor growth and invasion, promoting the proliferation of GC cells by enhancing the interaction between c-Myc mRNA and insulin-like growth factor 2 binding protein 1 (34). Additionally, GHET1 overexpression promotes the development of multidrug resistance, which is associated the expressions B-cell lymphoma 2 (Bcl-2), Bcl-2-associated X, MDR, and multidrug resistance-associated protein 1 genes in GC cells (35). LncRNA urothelial cancer-associated 1 increases the metastatic ability of GC cells by regulating GRK2 protein stability via Cbl-c-mediated GRK2 ubiquitination and degradation (36).

The authors of the present study have previously reported that novel lncRNA STCAT3 was highly expressed in GC tissues, was able to promote the proliferation, migration and invasion of GC cells in vitro and promote the growth of transplanted tumors in vivo (12). The results of the present study support these findings. It was also demonstrated that STCAT3 expression was significantly upregulated in GC compared with paired adjacent tissues. STCAT3 upregulation in patients with GC was positively correlated with advanced TNM stage and lymph node metastasis. Furthermore, high STCAT3 expression in GC tissues was associated with poor prognosis. These results suggest that STCAT3 may function as an oncogene in GC.

To further identify the molecular mechanisms and binding partners of STCAT3, mass spectrometry was performed in BGC-823 cells followed by an RNA pull-down assay. The results demonstrated that STCAT3 interacts with dermcidin, which was further verified by RT-qPCR and western blotting. The results were also verified using an RIP-qPCR assay and it was demonstrated that STCAT3 could be enriched in dermcidin precipitates, indicating that dermcidin is a novel binding protein of lncRNA STCAT3.

A number of studies have reported that dermcidin serves a role in the carcinogenesis of a number of tumor types, including lung cancer $(16,37)$, melanoma $(17,38)$, breast cancer (39-41), hepatocellular carcinoma (HCC) $(42,43)$, prostatic carcinoma (44) and pancreatic cancer (15). Dermcidin may also affect breast cancer development through the ERBB signaling pathway (41).

Immunohistochemical results revealed that, compared with pair-matched normal gastric tissues, dermcidin was overexpressed in GC. Furthermore, the dermcidin expression 
was significantly correlated with clinical TNM stage, tumor differentiation and lymph node metastasis. Importantly, a positive correlation was observed between the expression of STCAT3 and dermcidin in GC tissues. The median time until postoperative recurrence was increased in the low dermcidin expression group, as was the OS duration. These results indicate that dermcidin overexpression is a predictor of poor prognosis in patients with GC.

The present study is not without limitations. Although it was determined that dermcidin is the interaction protein of lncRNA STAT3, the mechanism that leads to the formation of lncRNA STCAT3 remain to be elucidated. Furthermore, the sample size used in the present study was small. These limitations should be addressed in future studies.

In summary, the results of the present study indicate that dermcidin is a novel binding protein of IncRNA STCTA3, which serves an important role in cancer progression and patient clinical outcomes in GC. The results of the present study provide a theoretical basis for follow-up studies investigating the regulatory mechanism of lncRNA STCAT3 in the occurrence and development of GC and its potential as a molecular therapeutic target.

\section{Acknowledgements}

Not applicable.

\section{Funding}

The present study was funded by the Youth Foundation of Affiliated Hospital of Nantong University (grant no. TDFY033 2), the Hospital Talent Training Foundation (grant no. 2015-68), the Youth Foundation of Nantong Municipal Commission of Health and Family Planning (grant no. WQ2016079) and Jiangsu Province's Key Young Medicine Talents Program of Ding (grant no. QNRC2016688), China Postdoctoral Science Foundation (grant no. 2018M630592).

\section{Availability of data and materials}

The datasets used during the present study are available from the corresponding author upon reasonable request.

\section{Authors' contributions}

JZ, WD, ZM and ZW conceived and designed the study. JZ, $\mathrm{WD}, \mathrm{XK}, \mathrm{YJ}$ and $\mathrm{ZZ}$ performed the experiments. JZ and WD wrote the manuscript. $\mathrm{ZM}$ and $\mathrm{ZW}$ reviewed and edited the manuscript. All authors read and approved the manuscript and agree to be accountable for all aspects of the research in ensuring that the accuracy or integrity of any part of the work are appropriately investigated and resolved.

\section{Ethics approval and consent to participate}

All procedures performed in this study involving human participants were in accordance with the 1964 Declaration of Helsinki and its later amendments or comparable ethical standards. The ethical approval was obtained from the independent ethics committees at Affiliated Hospital of Nantong University.

\section{Patient consent for publication}

Not applicable.

\section{Competing interests}

The authors declare that they have no competing interests.

\section{References}

1. Siegel RL, Miller KD and Jemal A: Cancer Statistics, 2017. CA Cancer J Clin 67: 7-30, 2017.

2. Nie Y, Wu K, Yu J, Liang Q, Cai X, Shang Y, Zhou J, Pan K, Sun L, Fang J, et al: A global burden of gastric cancer: The major impact of China. Expert Rev Gastroenterol Hepatol 11: 651-661, 2017.

3. Ørom UA, Derrien T, Beringer M, Gumireddy K, Gardini A, Bussotti G, Lai F, Zytnicki M, Notredame C, Huang Q, et al: Long noncoding RNAs with enhancer-like function in human cells. Cell 143: 46-58, 2010.

4. Quinn JJ and Chang HY: Unique features of long non-coding RNA biogenesis and function. Nat Rev Genet 17: 47-62, 2016.

5. Wilusz JE, Sunwoo H and Spector DL: Long noncoding RNAs: Functional surprises from the RNA world. Genes Dev 23: 1494-1504, 2009.

6. Bartonicek N, Maag JL and Dinger ME: Long noncoding RNAs in cancer: Mechanisms of action and technological advancements. Mol Cancer 15: 43, 2016.

7. Nam JW, Choi SW and You BH: Incredible RNA: Dual functions of coding and noncoding. Mol Cells 39: 367-374, 2016.

8. Huang JZ, Chen M, Chen, Gao XC, Zhu S, Huang H, Hu M, Zhu H and Yan GR: A peptide encoded by a putative lncRNA HOXB-AS3 suppresses colon cancer growth. Mol Cell 68: 171-184.e6, 2017.

9. Matsumoto A, Pasut A, Matsumoto M, Yamashita R, Fung J, Monteleone E, Saghatelian A, Nakayama KI, Clohessy JG and Pandolfi PP: mTORC1 and muscle regeneration are regulated by the LINC00961-encoded SPAR polypeptide. Nature 541: 228-232, 2017.

10. Roberts TC, Morris KV and Weinberg MS: Perspectives on the mechanism of transcriptional regulation by long non-coding RNAs. Epigenetics 9: 13-20, 2014.

11. Gibb EA, Brown CJ and Lam WL: The functional role of long non-coding RNA in human carcinomas. Mol Cancer 10: 38, 2011.

12. Zhang JF, Sun ZS, Zhang QF, Ding WF, Wu XH and Mao ZB: Expression of long noncoding RNA STCAT3 in gastric cancer tissues and its effect on malignant phenotype of gastric cancer cells. Zhonghua Yi Xue Za Zhi 96: 3735-3740, 2016 (In Chinese).

13. Zhang JF, Qu LS, Qian XF, Xia BL, Mao ZB and Chen WC: Nuclear transcription factor CDX2 inhibits gastric cancer-cell growth and reverses epithelial-to-mesenchymal transition in vitro and in vivo. Mol Med Rep 12: 5231-5238, 2015.

14. Guan C, Zhang J, Zhang J, Shi H and Ni R: Enhanced expression of early mitotic inhibitor-1 predicts a poor prognosis in esophageal squamous cell carcinoma patients. Oncol Lett 12: 114-120, 2016.

15. Stewart GD, Skipworth RJ, Pennington CJ, Lowrie AG, Deans DA, Edwards DR, Habib FK, Riddick AC, Fearon KC and Ross JA: Variation in dermcidin expression in a range of primary human tumours and in hypoxic/oxidatively stressed human cell lines. Br J Cancer 99: 126-132, 2008.

16. Chang WC, Huang MS, Yang CJ, Wang WY, Lai TC, Hsiao M and Chen CH: Dermcidin identification from exhaled air for lung cancer diagnosis. Eur Respir J 35: 1182-1185, 2010.

17. Ortega-Martínez I, Gardeazabal J, Erramuzpe A, Sanchez-Diez A, Cortés J, García-Vázquez MD, Pérez-Yarza G, Izu R, Luís Díaz-Ramón J, de la Fuente IM, et al: Vitronectin and dermcidin serum levels predict the metastatic progression of AJCC I-II early-stage melanoma. Int J Cancer 139: 1598-1607, 2016.

18. Yun J, Mullarky E, Lu C, Bosch KN, Kavalier A, Rivera K, Roper J, Chio II, Giannopoulou EG, Rago C, et al: Vitamin C selectively kills $K R A S$ and $B R A F$ mutant colorectal cancer cells by targeting GAPDH. Science 350: 1391-1396, 2015. 
19. Wang CY, Chen CL, Tseng YL, Fang YT, Lin YS, Su WC, Chen CC, Chang KC, Wang YC and Lin CF: Annexin A2 silencing induces $\mathrm{G}_{2}$ arrest of non-small cell lung cancer cells through p53-dependent and -independent mechanisms. J Biol Chem 287: 32512-32524, 2012.

20. Feng X, Liu H, Zhang Z, Gu Y, Qiu H and He Z: Annexin A2 contributes to cisplatin resistance by activation of JNK-p53 pathway in non-small cell lung cancer cells. J Exp Clin Cancer Res 36: 123, 2017.

21. Rogers MS, Foley MA, Crotty TB, Hartmann LC, Ingle JN, Roche PC and Strehler EE: Loss of immunoreactivity for human calmodulin-like protein is an early event in breast cancer development. Neoplasia 1: 220-225, 1999.

22. Brooks MD, Bennett RD, Strehler EE, Sebo TJ, Eckert SE and Carr AB: Human calmodulin-like protein (CLP) expression in oral squamous mucosa and in malignant transformation. J Prosthodont 18: 11-16, 2009.

23. Yang L, Cui M, Zhang L and Song L: FOXM1 facilitates gastric cancer cell migration and invasion by inducing Cathepsin D. Oncotarget 8: 68180-68190, 2017.

24. Zhu J, Wu G, Li Q, Gong H, Song J, Cao L, Wu S, Song L and Jiang L: Overexpression of suprabasin is associated with proliferation and tumorigenicity of esophageal squamous cell carcinoma. Sci Rep 6: 21549, 2016.

25. Miller KD, Siegel RL, Lin CC, Mariotto AB, Kramer JL, Rowland JH, Stein KD, Alteri R and Jemal A: Cancer treatment and survivorship statistics, 2016. CA Cancer J Clin 66: 271-289, 2016.

26. Huarte M: The emerging role of lncRNAs in cancer. Nat Med 21: $1253-1261,2015$.

27. Schmitt AM and Chang HY: Long Noncoding RNAs in cancer pathways. Cancer Cell 29: 452-463, 2016.

28. Gupta RA, Shah N, Wang KC, Kim J, Horlings HM, Wong DJ, Tsai MC, Hung T, Argani P, Rinn JL, et al: Long non-coding RNA HOTAIR reprograms chromatin state to promote cancer metastasis. Nature 464: 1071-1076, 2010.

29. Arab K, Park YJ, Lindroth AM, Schäfer A, Oakes C, Weichenhan D, Lukanova A, Lundin E, Risch A, Meister M, et al: Long noncoding RNA TARID directs demethylation and activation of the tumor suppressor TCF21 via GADD45A. Mol Cell 55: 604-614, 2014.

30. Gooding AJ, Zhang B, Jahanbani FK, Gilmore HL, Chang JC, Valadkhan S and Schiemann WP: The lncRNA BORG drives breast cancer metastasis and disease recurrence. Sci Rep 7 : 12698, 2017.

31. Lu X, Huang C, He X, Liu X, Ji J, Zhang E, Wang W and Guo R: A novel long non-coding RNA, SOX21-AS1, indicates a poor prognosis and promotes lung adenocarcinoma proliferation. Cell Physiol Biochem 42: 1857-1869, 2017.

32. Yu X and Li Z: Long non-coding RNA HOTAIR: A novel oncogene (Review). Mol Med Rep 12: 5611-5618, 2015.
33. Chen WM, Chen WD, Jiang XM, Jia XF, Wang HM, Zhang QJ, Shu YQ and Zhao HB: HOX transcript antisense intergenic RNA represses E-cadherin expression by binding to EZH2 in gastric cancer. World J Gastroenterol 23: 6100-6110, 2017.

34. Yang F, Xue X, Zheng L, Bi J, Zhou Y, Zhi K, Gu Y and Fang G: Long non-coding RNA GHET1 promotes gastric carcinoma cell proliferation by increasing c-Myc mRNA stability. FEBS J 281: 802-813, 2014

35. Zhang X, Bo P, Liu L, Zhang X and Li J: Overexpression of long non-coding RNA GHET1 promotes the development of multidrug resistance in gastric cancer cells. Biomed Pharmacother 92: 580-585, 2017.

36. Wang ZQ, He CY, Hu L, Shi HP, Li JF, Gu QL, Su LP, Liu BY, Li C and Zhu Z: Long noncoding RNA UCA1 promotes tumour metastasis by inducing GRK2 degradation in gastric cancer. Cancer Lett 408: 10-21, 2017.

37. López-Sánchez LM, Jurado-Gámez B, Feu-Collado N, Valverde A, Cañas A, Fernández-Rueda JL, Aranda E and Rodríguez-Ariza A: Exhaled breath condensate biomarkers for the early diagnosis of lung cancer using proteomics. Am J Physiol Lung Cell Mol Physiol 313: L664-L676, 2017.

38. Trzoss L, Fukuda T, Costa-Lotufo LV, Jimenez P, La Clair JJ and Fenical W: Seriniquinone, a selective anticancer agent, induces cell death by autophagocytosis, targeting the cancer-protective protein dermcidin. Proc Natl Acad Sci USA 111: 14687-14692, 2014.

39. Moreira DF, Strauss BE, Vannier E and Belizário JE: Genes upand down-regulated by dermcidin in breast cancer: A microarray analysis. Genet Mol Res 7: 925-932, 2008.

40. Brauer HA, D'Arcy M, Libby TE, Thompson HJ, Yasui YY, Hamajima N, Li CI, Troester MA and Lampe PD: Dermcidin expression is associated with disease progression and survival among breast cancer patients. Breast Cancer Res Treat 144: 299-306, 2014

41. Bancovik J, Moreira DF, Carrasco D, Yao J, Porter D, Moura R, Camargo A, Fontes-Oliveira CC, Malpartida MG, Carambula S, et al: Dermcidin exerts its oncogenic effects in breast cancer via modulation of ERBB signaling. BMC Cancer 15: 70, 2015.

42. Lowrie AG, Dickinson P, Wheelhouse N, Stewart GD, Ross AJ, Forster T and Ross JA: Proteolysis-inducing factor core peptide mediates dermcidin-induced proliferation of hepatic cells through multiple signalling networks. Int J Oncol 39: 709-718, 2011.

43. Shen SL, Qiu FH, Dayarathna TK, Wu J, Kuang M, Li SS, Peng BG and Nie J: Identification of Dermcidin as a novel binding protein of Nck1 and characterization of its role in promoting cell migration. Biochim Biophys Acta 1812: 703-710, 2011.

44. Stewart GD, Lowrie AG, Riddick AC, Fearon KC, Habib FK and Ross JA: Dermcidin expression confers a survival advantage in prostate cancer cells subjected to oxidative stress or hypoxia. Prostate 67: 1308-1317, 2007. 